\title{
Pengaruh Likuiditas Dan Profitabilitas Perusahaan Terhadap Firm's Value Pada Perusahaan Yang Melakukan IPO Di Tahun 2018
}

\author{
1Rudy \\ ${ }^{1}$ Dosen Akuntansi, STIE Bisnis Indonesia, Jakarta Selatan, Indonesia \\ e-mail: rudy@stiebi.ac.id
}

\begin{abstract}
Abstrak. Penelitian ini bertujuan untuk menganalisis pengaruh likuiditas dan profitabilitas perusahaan terhadap firm's value. Firm's value diukur dengan pendekatan price-to book value (PBV). Populasi penelitian ini adalah perusahaan yang melakukan initial public offerings (IPO) pada tahun 2018. Penentuan sampel dilakukan dengan teknik purposive sampling. Metode analisis menggunakan analisis statistik inferensial dengan regresi linear berganda menggunakan program SPSS 23.00 for Windows. Hasil penelitian ini menunjukkan bahwa likuiditas dan profitabilitas perusahaan berpengaruh signifikan secara simultan terhadap firm's value. Hasil pengujian secara parsial menunjukkan bahwa likuiditas perusahaan berpengaruh negatif dan tidak signifikan terhadap firm's value sementara profitabilitas perusahaan berpengaruh positif dan signifikan terhadap firm's value.
\end{abstract}

\section{PENDAHULUAN}

\section{Latar Belakang}

Fenomena saat ini firm's value merupakan hal yang penting bagi perusahaan yang sahamnya go public dengan penetapan harga perdana berdasarkan harga saham melalui initial public offerings (IPO). Sejak bergabungnya Indonesia dalam Masyarakat Ekonomi ASEAN (MEA) pada tahun 2016 se Asia Tenggara dan tantangan Revolusi Industri 4.0 dengan menyelaraskan peta jalan sektor-sektor industri yang menjadi fokus dalam Making Indonesia 4.0 (Kementerian Perindustrian Republik Indonesia, 2018). Sejak BEI mengalami privatisasi di tahun 1992, sepanjang tahun 2018 hingga awal November 201850 (lima puluh) emiten baru yang menjadi rekor pencatatan saham di Bursa Efek Indonesia (BEI) (Wareza, 2018). Kinerja untuk mengukur kesehatan keuangan dalam konteks moneter dapat digunakan untuk membandingkan kinerja perusahaan di dalam industri atau lintas sektor industri tertentu. Minat emiten pada IPO didorong oleh kondisi ekonomi nasional dan global yang baik serta mendukungnya kebijakan moneter seperti suku bunga yang rendah agar investor mengalihkan investasi dari Pasar Uang ke Pasar Modal (Hendrayana, 2018).

Likuiditas menurut Fred Weston (Kasmir, 2016, hal. 129) rasio yang menggambarkan kemampuan perusahaan untuk memenuhi kewajiban (utang) jangka pendek, jika perusahaan ditagih maka akan mampu membayar utang khususnya yang telah jatuh tempo. Semakin tinggi rasio ini maka semakin besar 
penjaminan aset lancar terhadap hutang lancar yang berimplikasi pada nilai aset lancar yang hanya digunakan untuk menjamin hutang jangka pendek suatu perusahaan (Horne, 2012, hal. 167).

Penelitian ini dilatarbelakangi oleh studi pada perusahaan yang listing di BEI antara lain: (1); studi pada perusahaan sektor industri barang konsumsi yang terdaftar di Bursa Efek Indonesia untuk mengetahui pengaruh rasio likuiditas dan rasio profitabilitas terhadap nilai perusahaan tahun 2012-2014 yang menggunakan variabel current ratio, quick ratio dan net profit margin $(C R, Q R$ dan NPM), variabel ROA dan ROE serta Tobins' $Q$ dengan melibatkan 37 perusahaan (Putri, Zahroh, \& Endang N.P., 2016); (2) studi pada perusahaan perbankan yang terdaftar di BEI untuk mengetahui dan memformulasi rekomendasi pengaruh profitabilitas, struktur modal dan likuiditas terhadap nilai perusahaan pada bank yang go-public periode tahun 2011-2014 yang menggunakan variabel ROE, DER dan LDR serta PBV dengan melibatkan 30 jumlah sampel (Lubis, Sinaga, \& Sasongko, 2017); dan (3) studi pada perusahaan manufaktur yang terdaftar di Indeks Saham Syari'ah Indonesia (ISSI) untuk mengetahui mengetahui pengaruh profitabilitas dan likuiditas terhadap nilai perusahaan dengan kebijakan dividen sebagai pemoderasi periode 2014-2016 yang menggunakan variabel ROA dan cash ratio (CR) dan price-to book value melibatkan 13 perusahaan (Dayanti, 2018).

Ketiga hasil penelitian di atas memiliki beberapa keterbatasan, yaitu: (1) masih terdapat hasil penelitian yang tidak konsisten; (2) penggunaan model pengukuran rasio profitabilitas menggunakan beberapa rasio keuangan; dan (3) subjek penelitian tidak melibatkan perusahaan-perusahaan yang melakukan penawaran saham perdana (IPO) sebagai starting-point pengukuran firm's value bagi perusahaan publik.

\section{Tujuan khusus penelitian}

Tujuan dalam penelitian ini adalah untuk mengetahui secara langsung pengaruh likuiditas dan profitabilitas perusahaan terhadap firm's value pada perusahaan yang melakukan initial public offerings (IPO) di tahun 2018.

\section{TINJAUAN PUSTAKA}

Rasio likuiditas adalah salah satu rasio yang mengacu pada kemampuan suatu perusahaan untuk memenuhi kewajiban keuangan jangka pendeknya. Rasio lancar digunakan yang mengukur aset lancar yang tersedia untuk memenuhi kewajiban lancar (Subramanyam, 2014, hal. 36). Likuiditas berbanding terbalik dengan profitabilitas yaitu peningkatan likuiditas biasanya diikuti dengan penurunan profitabilitas karena adanya kelebihan aset produktif yang tidak dimanfaatkan oleh perusahaan, maka diperlukan pengelolaan kebijakan modal kerja yang optimal supaya perusahaan tetap likuid dan tidak terganggu pada profitabilitasnya (Horne, 2012). Membandingkan kas dan asetaset yang dapat diubah dalam bentuk kas pada tahun dimana kewajiban jatuh tempo dan akan dibayar pada tahun itu juga. Rumus current ratio dapat dinyatakan sebagai berikut: 


$$
\mathrm{CR}=\frac{\text { Current Assets }}{\text { Current Liabilites }}
$$

(Subramanyam, 2014, hal. 546)

Rasio profitabilitas adalah salah satu rasio yang memiliki tujuan dan manfaat bagi pihak eksternal perusahaan. Tujuan penggunaan rasio profitabilitas bagi perusahaan maupun pihak luar perusahaan yaitu: (1) mengukur atau menghitung laba yang diperoleh perusahaan dalam satu periode tertentu; (2) menilai posisi laba perusahaan tahun sebelumnya dengan tahun sekarang; (3) menilai perkembangan laba dari waktu ke waktu; dan (4) menilai besarnya laba bersih sesudah pajak dengan modal sendiri (Kasmir, 2016, hal. 196).

\begin{tabular}{|c|c|}
\hline Return on Asset & $=\frac{\text { Laba Bersih }}{\text { Total Aset }}$ \\
\hline
\end{tabular}

(Kasmir, 2016, hal. 201)

Nilai perusahaan adalah rasio dari nilai pasar dari aset perusahaan (Kumar, 2016, hal. 197). Salah satu pengukuran untuk melihat nilai perusahaan menggunakan Tobin's $Q$. Tobin's $Q$ dihitung dengan membandingkan rasio nilai pasar saham perusahaan dengan nilai buku entitas perusahaan.

$$
q=\frac{(E M V+D)}{(E B V+\mathrm{D})}
$$

Keterangan:

$\mathrm{q} \quad=$ nilai perusahaan

$\mathrm{EMV}=$ (nilai pasar ekuitas) yaitu closing price saham $\mathrm{x}$ jumlah saham yang beredar

$\mathrm{D} \quad=$ nilai buku dari total utang

$\mathrm{EBV}=$ nilai buku ekuitas dari total aset

(Weston \& Copeland, 2010, hal. 244)

Nilai perusahaan juga dapat diukur menggunakan pendekatan analisis rasio berdasarkan nilai pasar (market value) yang terdiri dari price earnings ratio (PER), price book value ratio (PBVR), market book ratio (MBR), dividend yield ratio, dan dividend payout ratio (Brigham \& Houston, 2014, hal. 150) Penelitian ini mengukur nilai perusahaan dengan rasio price book value (PBV). Pengukuran rasio ini menjadi sangat penting bagi investor untuk menentukan strategi porfolio di pasar modal (Mayogi \& Fidiana, 2016). PBV

$$
\text { PBV }=\frac{\text { Price Market per Share }}{\text { Book Value per Share }}
$$

dapat dihitung dengan harga pasar saham terhadap nilai buku setiap lembar saham dengan rumus sebagai berikut:

(Brigham \& Houston, 2014) 


\section{Jurnal Buana Akuntansi}

Kerangka Pemikiran

X1. Likuiditas Perusahaan

X2. Profitabiltias Perusahaan

FIRM'S VALUE

Gambar 2. Model Penelitian

\section{Hipotesis Penelitian}

H1 = Likuiditas Perusahaan berpengaruh signifikan terhadap Firm's Value

H2 = Profitabilitas Perusahaan berpengaruh signifikan terhadap Firm's Value

\section{METODE PENELITIAN}

Subjek penelitian

Subjek dalam penelitian ini adalah perusahaan yang terdaftar di Bursa Efek Indonesia (BEI) yang melakukan initial public offerings (IPO).

Jenis dan sumber data

Data yang dikumpulkan adalah data primer dan sekunder. Data primer adalah adalah responden individu, kelompok fokus, dan panel yang secara khusus ditentukan oleh peneliti dan di mana pendapat mereka terkait persoalan tertentu dapat dicari dari waktu ke waktu, atau sumber yang tidak begitu jelas seperti majalah atau buku-buku lama. Data sekunder adalah data yang diperoleh dari sumber sekunder, misalnya, catatan atau dokumentasi perusahaan, publikasi pemerintah, analisis industri yang diberikan oleh media, web, internet dan lainnya (Sekaran \& Bougie, 2017, hal. 130)."

\section{Populasi dan Sampel Penelitian}

Populasi dalam penelitian ini adalah perusahaan yang melakukan initial public offerings (IPO) yaitu sebanyak 56 perusahaan. Teknik pemilihan sampel menggunakan metode purposive sampling dengan kriteria: (1) perusahaan melakukan IPO di tahun 2018; dan (2) memiliki akses data lengkap selama tahun 2018. 
Table 1. Sampel Penelitian

\begin{tabular}{ccc}
\hline Kode & Nama Perusahaan & Tanggal IPO \\
Emiten & & \\
\hline LCKM & PT LCK Global Kedaton, Tbk. & 16-Jan-2018 \\
BOSS & PT Borneo Olah Sarana Sukses, Tbk. & 15-Feb-2018 \\
HELY & PT Jaya Trishindo, Tbk. & 27-Mar-2018 \\
JSKY & PT Sky Energy Indonesia, Tbk. & 28-Mar-2018 \\
INPS & PT Indah Prakasa Sentosa, Tbk. & 06-Apr-2018 \\
TDPM & PT Tridomain Perfomance Materials, Tbk. & 09-Apr-2018 \\
GHON & PT Gihon Telekomunikasi Indonesia, Tbk. & 09-Apr-2018 \\
DFAM & PT Dafam Property Indonesia, Tbk. & 27-Apr-2018 \\
NICS & PT Charnic Capital, Tbk. & 02-Mei-2018 \\
BTPS & PT Tabungan Pensiun Nasional Syariah, Tbk. & 08-Mei-2018 \\
SPTO & PT Surya Pertiwi, Tbk. & 14-Mei-2018 \\
PRIM & PT Royal Prima, Tbk. & 15-Mei-2018 \\
HEAL & PT Medikaloka Hermina, Tbk. & 16-Mei-2018 \\
PZZA & PT Guna Timur Raya Kencana, Tbk. & 23-Mei-2018 \\
TRUK & PT Asuransi Tugu Pratama Indonesia, Tbk. & 23-Mei-2018 \\
TUGU & PT Sarimelati Kencana, Tbk. & 23-Mei-2018 \\
KPAL & PT Steadfast Marine, Tbk. & 08-Jun-2018 \\
SWAT & PT Sriwahana Adityakarta, Tbk. & 08-Jun-2018 \\
MSIN & PT MNC Studios International, Tbk. & 08-Jun-2018 \\
TNCA & PT Trimuda Nuansa Citra, Tbk. & 28-Jun-2018 \\
MAPA & PT MAP Aktif Adiperkasa, Tbk. & 05-Jul-2018 \\
TCPI & PT Transcoal Pacific, Tbk. & 06-Jul-2018 \\
BPTR & PT Batavia Prosperindo Trans, Tbk. & 09-Jul-2018 \\
RISE & PT Jaya Sukses Makmur Sentosa, Tbk. & 09-Jul-2018 \\
IPCC & PT Indonesia Kendaraan Terminal, Tbk. & 09-Jul-2018 \\
POLL & PT Pollux Properti Indonesia, Tbk. & 11-Jul-2018
\end{tabular}


NUSA

MGRO

NFCX

FILM

ANDI

LAND

MOLI

DIGI

PANI

CITY

SAPX

SURE

KPAS

MPRO

HKMU

GOOD

DUCK

SKRN

YELO

CAKK

SATU

SOSS

DEAL

POLA

DIVA

LUCK

SOTS

URBN

ZONE

PEHA
PT Sinergi Megah Internusa, Tbk.

PT Mahkota Group, Tbk.

PT NFC Indonesia, Tbk.

PT MD Pictures, Tbk.

PT Andira Agro, Tbk.

PT Trimitra Propertindo, Tbk.

PT Madusari Murni Indah, Tbk.

PT Arkadia Digital Media, Tbk.

PT Pratama Abadi Nusa Industri, Tbk.

PT Natura City Development, Tb

PT Satria Antaran Prima, Tbk.

PT Super Energy, Tbk.

PT Cottonindo Ariesta, Tbk.

PT Propertindo Mulia Investama, Tbk. PT HK Metals Utama, Tbk.

PT Garudafood Putra Putri Jaya, Tbk. PT Jaya Bersama Indo, Tbk.

PT Superkrane Mitra Utama, Tbk.

. PT Yelooo Integra Datanet, Tbk.

PT Cahayaputra Asa Keramik, Tbk.

PT Kota Satu Properti, Tbk.

PT Shield On Services, Tbk.

PT Dewata Freight International, Tbk. PT Pool Advista Finance, Tbk.

PT Distribusi Voucher Nusantara, Tbk.

PT Sentral Mitra Informatika, Tbk.

PT Satria Mega Kencana, Tbk.

PT Urban Jakarta Propertindo, Tbk.

PT Mega Perintis, Tbk.

PT Phapros, Tbk.

Jumlah
12-Jul-2018

12-Jul-2018

12-Jul-2018

07-Agus-2018

16-Agus-2018

23-Agus-2018

30-Agus-2018

18-Sept-2018

18-Sept-2018

28-Sept-2018

03-Okt-2018

05-Okt-2018

05-Okt-2018

09-Okt-2018

09-Okt-2018

10-Okt-2018

10-Okt-2018

11-Okt-2018

29-Okt-2018

31-Okt-2018

05-Nov-2018

06-Nov-2018

09-Nov-2018

16-Nov-2018

27-Nov-2018

28-Nov-2018

10-Des-2018

10-Des-2018

12-Des-2018

26-Des-2018

56

(Sumber: Data BEI, 2018)

\section{Metode Analisis Data}

Metode analisis data dalam penelitian ini menggunakan teknik regresi linear berganda. Pengujian ini mensyaratkan setelah model regresi yang diajukan lolos dari pengujian asumsi klasik melalui analisis persamaan regresi berganda, koefisien determinasi ( $R$ Square), uji hipotesis melalui uji simultan (Uji-F), dan uji signifikansi parameter individual (Uji-t). Adapun persamaan regresi berganda dirumuskan sebagai berikut: $\mathrm{Y}=\alpha+\beta 1 . \mathrm{X} 1+\beta 2 . \mathrm{X} 2+\mathrm{è}$

\section{Keterangan :}

\begin{tabular}{ll}
\hline $\mathrm{Y}$ & $:$ Firm's Value \\
$\mathrm{a}$ & $:$ Konstanta \\
$\beta 1-\beta 2$ & : Koefisien regresi masing-masing variabel \\
independen X1 & : Likuiditas Perusahaan \\
$\mathrm{X} 2$ & : Profitabilitas \\
Perusahaan è & : Faktor \\
Penganggu &
\end{tabular}




\section{Hasil dan Pembahasan}

Penelitian ini menggunakan teknik analisis regresi linier berganda untuk menghindari bias dalam interpretasi data yang dapat mempengaruhi data lainnya terlebih dahulu dilakukan

screening data untuk mendeteksi adanya outlier. Menurut Hair (1998) untuk kasus sampel kecil (kurang dari 80), maka standar skor dengan nilai $\geq 2,5$ dinyatakan outlier (Ghozali, 2017, hal. 41). Hasil seleksi terhadap 54 (lima puluh empat) perusahaan yang menjadi anggota dari populasi, dimana: (1) 2 perusahaan dieliminasi karena tidak memiliki data lengkap yang digunakan untuk objek penelitian yaitu PT Jaya Trishindo, Tbk. dan PT Sky Energy Indonesia, Tbk.; dan (2) 3 data observasi memiliki Z-score yang lebih besar dari 2,5.

Tabel 2 Nilai Skor Outlier

\begin{tabular}{cccc} 
Observasi ke- & Kode Emiten & Nama Variabel & Z-Score \\
\hline 7 & NICK & ZX1 & 6,65161117063084 \\
27 & NFCX & ZX2 & 5,06996275078648 \\
36 & SURE & ZY & 4,60722392087365 \\
\hline
\end{tabular}

(Sumber: Data Diolah SPSS 23.00, 2018)

Oleh karena kedua faktor di atas, data tersebut dikeluarkan dari penetapan sampel awal. Dengan demikian, jumlah data sampel yang akan diolah pada pengujian selanjutnya berjumlah 51 perusahaan.

\subsection{Statistik Deksriptif}

Tabel 3 Statistik Deskriptif Variabel Penelitian Descriptive Statistics

\begin{tabular}{|l|r|r|r|r|r|}
\hline & $\mathrm{N}$ & $\begin{array}{l}\text { Minimu } \\
\mathrm{m}\end{array}$ & $\begin{array}{r}\text { Maximu } \\
\mathrm{m}\end{array}$ & Mean & \multicolumn{1}{l}{$\begin{array}{l}\text { Std. } \\
\text { Deviation }\end{array}$} \\
\hline Likuiditas Perusahaan & 51 &, 1 & 17,2 & 3,148 & 3,3524 \\
Profitabilitas & 51 &, 01 & 2,19 &, 3307 &, 37486 \\
Perusahaan & 51 &, 10 & 32,90 & 5,4229 & 6,12098 \\
Firm's Value & 51 & & & & \\
Valid N (listwise) & & & & \\
\hline
\end{tabular}

(Sumber: Output SPSS 23.00, 2018)

Hasil statistik deskriptif menunjukkan bahwa variabel likuiditas perusahaan (X1) memiliki nilai interval terendah dan tertinggi pada 0,1 dan 17,2 kali dengan rata-rata 3,148 kali, artinya kas dan aset-aset yang dapat diubah dalam bentuk kas pada tahun 2018 memiliki tingkat likuiditas yang baik. Hasil statistik deskriptif menunjukkan bahwa variabel profitabilitas perusahaan (X2) memiliki nilai interval terendah dan tertinggi pada 0,01 dan 2,19 kali dengan rata-rata 0,3307 persen, artinya tingkat pengembalian laba bersih atas rata-rata keseluruhan aset yang dimiliki perusahaan cukup tinggi yaitu 33,07 persen. Hasil statistik deskriptif menunjukkan bahwa variabel 


\section{Jurnal Buana Akuntansi}

firm'v value (Y) dengan proksi price-to book value untuk mengukur nilai perusahaan memiliki nilai rata-rata sebesar 5,4229 dengan nilai interval terendah dan tertinggi pada 0,10 dan 32,90. Nilai rata-rata PBV perusahaan 5,4229 dengan standar deviasi sebesar 6,12098, hal ini dapat dipahami bahwa variasi data pada sampel perusahaan yang diteliti juga cukup besar (nilai mean dibandingkan dengan nilai standar deviasi lebih besar dari $30 \%)$.

\subsection{Uji Asumsi Klasik}

Uji asumsi klasik dilakukan melalui beberapa tahapan sebagai berikut:

\subsubsection{Uji Normalitas}

Uji normalitas dilakukan dengan analisis statistik non-parametrik melalui uji One- Sample Kolmogorov-Smirnov (K/S) dengan kriteria penerimaan hipotesis berikut ini:

$>$ H0: Nilai signifikansi (Asymp. Sig 2-tailed > a, maka data residual berdistribusi normal; dan

$>$ Ha: Nilai signifikansi (Asymp. Sig 2-tailed < a, maka data residual tidak berdistribusi normal $(\alpha=5 \%)$

\begin{tabular}{lc}
\multicolumn{1}{c}{ Tabel 4 Hasil Uji Normalitas } \\
& $\begin{array}{l}\text { Unstandardized } \\
\text { Residual }\end{array}$ \\
Jumlah Sampel (n) & 51 \\
Nilai Kolmogorov- & 1,516 \\
Smirnov Z & \\
Asymp. Sig 2-tailed & 0,020 \\
\hline
\end{tabular}




\section{Jurnal Buana Akuntansi}

Besaran nilai Kolmogorov-Smirnov Z untuk variabel firm's value adalah sebesar 1,516 dan Asymp. Sig (2-tailed) sebesar 0,020 adalah signifikan sehingga $\mathrm{H}_{0}$ ditolak $(\mathrm{p}<0,05)$. Dengan demikian, hasil uji normalitas data pada penelitian ini dapat disimpulkan bahwa data berasal dari populasi yang tidak berdistribusi normal. Hasil Output SPSS 23.00 menunjukkan bahwa firm's value memiliki tampilan histogram yang cenderung menceng ke kiri (positive skewness) (Ghozali, 2017, hal. 34).

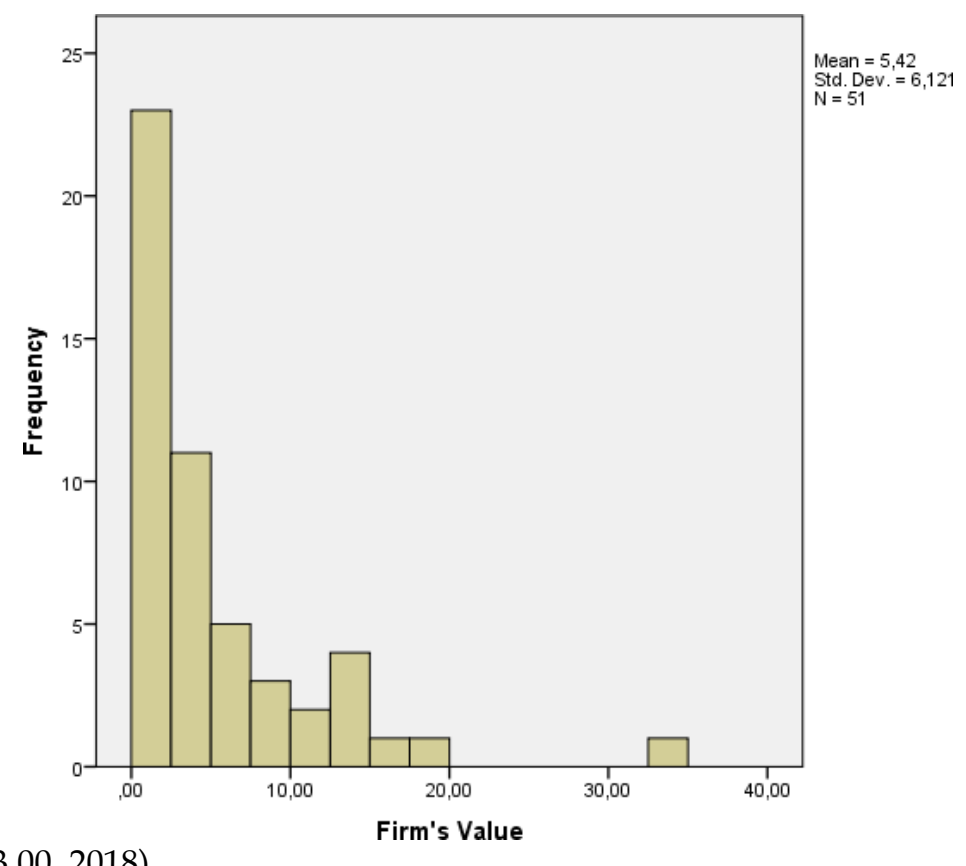

(Sumber: Output SPSS 23.00, 2018)

Gambar 2. Histogram Uji Normalitas

Untuk Permasalahan normalitas dapat diatasi dengan memberikan alternatif bentuk transformasi data dengan mengubah model regresi menjadi semi-log dalam bentuk logaritma natural menjadi persamaan regresi baru sebagai berikut:

Setelah dilakukan pengujian kembali Kolmogorov-Smirnov (K/S), dapat diketahui besarnya $\mathrm{Ln} \_\mathrm{Y}=\alpha+\beta 1 . \mathrm{Ln} \_\mathrm{X} 1+\beta 2 . \mathrm{Ln} \_\mathrm{X} 2+\mathrm{è}$

unstandardized residual:

Tabel 5 Hasil Uji Normalitas

\begin{tabular}{lc}
\cline { 2 - 2 } \multicolumn{1}{c}{ Unstandardized Residual } \\
Jumlah Sampel (n) & 51 \\
Nilai Kolmogorov-Smirnov Z Asymp. & 0,83 \\
Sig 2-tailed & 7 \\
(Sumber: Data Diolah SPSS 23.00, 2018) & 0,48 \\
& 5
\end{tabular}

Hasil uji Kolmogorov-Smirnov setelah dilakukan transformasi data diperoleh besaran nilai Kolmogorov-Smirnov Z untuk variabel Ln_Y, Ln_X1 dan Ln_X2 adalah sebesar 0,837 dan Asymp. Sig (2-tailed) sebesar 0,485 adalah tidak signifikan sehingga $\mathrm{H}_{0}$ diterima ( $\mathrm{p}>$ 0,05). Oleh karena itu, data residual telah memenuhi asumsi berdistribusi normal. 


\subsubsection{Uji Heteroskedastisitas}

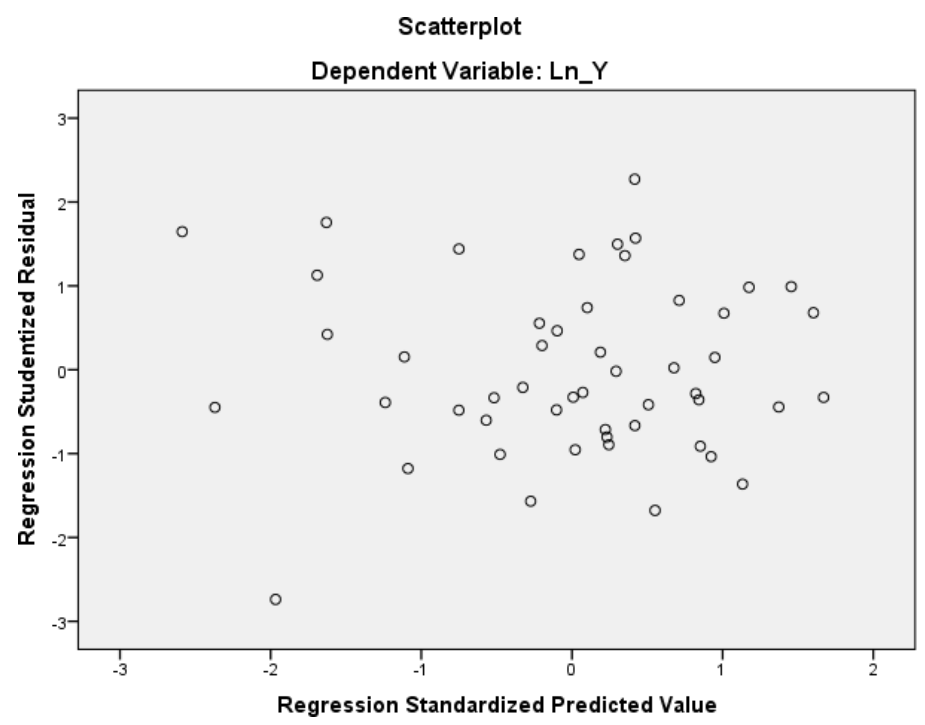

(Sumber: Output SPSS 23.00, 2018)

Gambar 3. Grafik Scatterplots

Grafik scatterplot dari variabel Firm's value yang ditransofmasikan ke dalam bentuk semi $\log$ menghasilkan sebaran titik-titik menyebar di atas dan di bawah angka 0 dan sumbu $Y$, yang berarti model dalam penelitian ini terbebas dari heteroskedastisitas antar variabel penelitian.

4.2.3. Uji Multikolinearitas

Uji multikolinearitas dilakukan dengan melihat besaran nilai tolerance dan VIF (varian inflated factor) dengan persyaratan bahwa nilai Tolerance $<0,10$ atau sama dengan nilai VIF $>10$.

Tabel 6 Hasil Uji Multikolinearitas

\begin{tabular}{cccc}
\hline Variabel Independen & \multicolumn{2}{c}{$\begin{array}{c}\text { Nilai } \\
\text { Tolerance }\end{array}$} \\
\cline { 2 - 4 } & Ln_X1 & 0,900 & 1,1010 \\
Ln_X2 & 0,990 & 1,1010 \\
\hline
\end{tabular}

(Sumber: Data Diolah SPSS 23.00, 2018)

Nilai tolerance pada variabel Ln_X1 dan Ln_X2 lebih besar (>) daripada 0,1 dan nilai VIF lebih kecil $(<)$ daripada 10 yang berarti model regresi terbebas dari masalah multikolonieritas antar variabel independen. 


\section{Jurnal Buana Akuntansi}

\subsubsection{Uji Koefisien Determinasi $\left(\mathrm{R}^{2}\right)$}

Tabel 7 Rangkuman Hasil Uji Koefisien Determinasi $\left(\mathrm{R}^{2}\right)$

\begin{tabular}{lllll}
\hline Model & $\begin{array}{l}\mathrm{R} \\
\text { Adjusted }\end{array}$ & & $\begin{array}{l}\text { SE of the } \\
\text { Estimate } \\
\mathrm{R}^{2}\end{array}$ & \\
\cline { 1 - 3 } & & & 0,084 & 1,04398 \\
\hline
\end{tabular}

(Sumber: Data Diolah SPSS 23.00, 2018)

Nilai koefisien determinasi $\left(R^{2}\right)$ diperoleh sebesar 0,121 yang berarti 12,1 persen perubahan dari variabel Ln_Y dijelaskan oleh variasi variabel Ln_X1 dan Ln_X2, sedangkan sisanya 87,9 persen dijelaskan oleh variabel lain yang tidak diikutsertakan dalam penelitian ini.

4.2.5. Uji ANNOVA

Tabel 8 Rangkuman Hasil Uji-F

Model df1 df2 F-

hitung

Probabilitas

Signifikansi

\begin{tabular}{lllll}
\hline 1 & 2 & 48 & 3,296 & 0,046 \\
\hline
\end{tabular}

(Sumber: Data Diolah SPSS 23.00, 2018)

Tabel 8 di atas menunjukkan bahwa nilai F-hitung sebesar 3,296 dengan probabilitas signifikansi yang lebih kecil $(<)$ dari alpha 5\%, yaitu 0,046, sehingga menolak $\mathrm{H}_{0}$. Variabel Ln_X1 dan Ln_X2 yang merupakan hasil tranformasi dari likuiditas perusahaan dan profitabilitas perusahaan secara simultan berpengaruh signifikan terhadap Firm's value.

4.2.6. Uji Signifikansi Parameter Individual Tabel 9 Rangkuman Hasil

\begin{tabular}{lllll}
\hline Uji-t Model & & \multicolumn{3}{c}{$\beta$ Sig. Keputusan } \\
\hline 1 (Constant) & & 1,737 & 0,000 & \\
& Ln_X1 & $-0,094$ & 0,496 & $\mathrm{H}_{1}$ ditolak
\end{tabular}


(Sumber: Data Diolah SPSS 23.00, 2018)

Hasil dari pengujian signifikansi parameter individual dituangkan pada persamaan regresi berganda sebagai berikut:

LN_Y $=1,737-0,094 L n \_X 1+0,307 L n \_X 2+$ è

Constant : 1,737. Artinya rata-rata kontribusi variabel independen selain Ln_X1 dan Ln_X2 juga memberikan dampak positif terhadap nilai Ln_Y.

Ln_X1 : -0,094. Artinya Ln_X1 memiliki pengaruh negatif terhadap Ln_Y, jika terjadi kenaikan Ln_X1 sebesar 1 (satu) kali dan variabel independen lainnya bernilai tetap, maka Ln_Y akan mengalami penurunan sebesar 9,4.

Ln_X2 : 0,307. Artinya Ln_X2 memiliki pengaruh positif terhadap Ln_Y, jika terjadi kenaikan Ln_X2 sebesar 1 (satu) persen dan variabel independen lainnya bernilai tetap, maka Ln_Y akan mengalami peningkatan sebesar 30,7 persen.

\subsection{Pembahasan}

Pengaruh likuiditas perusahaan terhadap firm's value menghasilkan probabilitas signifikansi sebesar 0,496 > 0,05 yang artinya likuiditas perusahaan yang tidak signifikan terhadap firm's value. Hasil penelitian hipotesis pertama mendukung penelitian yang tidak membuktikan pengaruh CR terhadap nilai perusahaan (Putri, Zahroh, \& Endang N.P., 2016; Lubis, Sinaga, \& Sasongko, 2017) dan mengkonfirmasi temuan pengaruh negatif likuiditas terhadap nilai perusahaan (Dayanti, 2018). Pengaruh profitabilitas perusahaan terhadap firm's value menghasilkan probabilitas signifikansi sebesar 0,015 < 0,05 yang artinya profitabilitas perusahaan signifikan terhadap firm's value. Hasil penelitian hipotesis kedua mendukung penelitian yang membuktikan pengaruh ROA dan ROE terhadap nilai perusahaan (Putri, Zahroh, \& Endang N.P., 2016; Lubis, Sinaga, \& Sasongko, 2017) sedangkan bertolak belakang yang tidak signifikan terhadap nilain perusahaan (Dayanti, 2018)

\section{Kesimpulan}

Berdasarkan hasil data dan pembahasan dapat disimpulkan bahwa likuiditas perusahaan berpengaruh negatif dan tidak signifikan terhadap firm's value sementara profitabilitas perusahaan berpengaruh positif dan signifikan terhadap firm's value. 
AE Surachman, Sutardjo

Vol 4 No 1

ISSN 2528-1119

E-ISSN 2580-5452

\section{Daftar Pustaka}

Brigham, E. F., \& Houston, J. F. (2014). Dasar-Dasar Manajemen Keuangan. Jakarta: Salemba Empat.

Dayanti. (2018). Pengaruh Profitabilitas dan Likuiditas Terhadap Nilai Perusahaan Dengan Kebijakan Dividen Sebagai Pemoderasi. Fakultas Ekonomi dan Bisnis. Universitas Muhammadiyah Surakarta.

Ghozali, I. (2017). Aplikasi Analisis Multivariate Dengan Program: IBM SPSS 23 (VIII ed.). Semarang: Badan Penerbit UNDIP.

Hendrayana, W. (2018, Desember 08). Kinerja Saham IPO DI Tahun 2018. Retrieved Nopember 11, 2018, from

https://www.infovesta.com/index/article/articleread;jsessionid= 76821D5F27B83D6ECA294AB14A9B8863.NGXB/d2effb67-40a1-41ae-9d0f$43 \mathrm{~b} 8664 \mathrm{~b} 944 \mathrm{c}$

Horne, J. G. (2012). Prinsip-Prinsip Manajemen Keuangan. Jakarta: Salemba Empat. Kasmir, D. (2016). Analisis Laporan Keuangan. Jakarta: PT. Rajagrafindo Persada. Kementerian Perindustrian Republik Indonesia. (2018). Pemerintah Keluarkan 10 Jurus Jitu Hadapi Revolusi Industri 4.0. Retrieved Oktober 22, 2019, from https:/ / kemenperin.go.id/artikel/19169/Pemerintah-Keluarkan-10-Jurus-JituHadapi- Revolusi-Industri-4.0

Kumar, R. B. (2016). Valuation of Indian Companies - An Analytical Perspective. AsianPasific Journal of Management Research and Innovation, 4 (1), 93-104.

Lubis, I. L., Sinaga, B. M., \& Sasongko, H. (2017). Pengaruh Profitabilitas, Struktur Modal, Dan Likuiditas Terhadap Nilai Perusahaan. Jurnal Aplikasi Bisnis dan Manajemen, 3 (3), 458-465.

Mayogi, D., \& Fidiana. (2016). Pengaruh Profitabilitas, Kebijakan Dividen dan Kebijakan Utang terhadap Nilai Perusahaan. Jurnal Ilmu dan Riset Akuntansi, 5 (1), 1-18.

Putri, R. H., Z. Z., \& Endang N.P., M. G. (2016). Pengaruh Rasio Likuiditas dan Rasio Profitabilitas Terhadap Nilai Perusahaan (Studi pada Perusahaan Sektor Industri Barang Konsumsi yang Terdaftar di BEI Tahun 2012-2014). Jurnal Administrasi Bisnis (JAB), 38 (2), 38-45.

Sekaran, U., \& Bougie, R. (2017). Metode Penelitian untuk Bisnis Pendekatan PengembanganKeahlian (6 ed.). Jakarta: Salemba Empat.

Subramanyam, K. (2014). Financial Statement Analysis (11th International Edition ed.). New York: McGraw-Hill.

Wareza, M. (2018, November 09). Rekor! Dalam Setahun Lebih 50 Perusahaan IPO pada 2018. Retrieved Oktober 22, 2019, from CNBC Indonesia: https://www.cnbcindonesia.com/ market/20181109125101-17-41373/rekor-dalamsetahun- lebih-50-perusahaan-ipo-pada-2018. Weston, J. F., \& Copeland, T. E. (2010).

Manajemen Keuangan. Jakarta: Salemba Empat.

Kabupaten Klungkung', E-Jurnal Akuntansi Universitas Udayana, vol. 14, no. 2, 2016.

[1] C. Cadbury, Report of the Committee on the Financial Aspects of orporate Governance. London: Gee and Co, 1992.

[2] Komite Nasional Kebijakan Governance, 'Pedoman Umum Good Corporate Governance'. Komite Nasional Kebijakan Governance, 2006. 
[3] Deputi Bidang Pengawasan, Peraturan Deputi Bidang Pengawasan Kementerian Koperasi dan Usaha Kecil dan Menengah Republik Indonesia No. 6 tentang Pedoman Penilaian Kesehatan Koperasi Simpan Pinjam dan Unit Simpan Pinjam Koperasi. Jakarta: Kementerian Koperasi dan Usaha Kecil dan menengah, 2016.

[4] U. Sekaran, Research Methods for Business (Metode Penelitian untuk Bisnis), 1st ed. Jakarta: Salemba Empat, 2006.

[5] I. Ghozali and H. Latan, Partial Least Squares: Konsep, Teknik dan Aplikasi Menggunakan Program SmartPLS 3.0 untuk Penelitian Empiris, 2nd ed. Semarang: Universitas Diponegoro, 2015.

[6] R. E. Dasuki, 'Kajian Good Corporate Governance Pada Koperasi Simpan Pinjam Dan Pembiayaan Syariah', Festival Riset Ilmiah Manajemen dan Akuntansi, Bandung, pp. 739-755, 2018.

[7] I. Ghozali, Structural Equation Modeling: Metode Alternatif dengan Partial Least Square (PLS). Semarang: Universitas Diponegoro, 2008. 